\title{
The Effect of a Summer Garden Program on the Nutritional Knowledge, Attitudes, and Behaviors of Children
}

\author{
S. Koch ${ }^{1}$, T.M. Waliczek ${ }^{2}$, and J.M. Zajicek ${ }^{3}$
}

AdDITIONAL INDEX WORDS. elementary school, nutrition, nutrition education, The Better Living for Texans program

Summary. Fifty-six children were included in a study that evaluated the effectiveness of a garden program designed to teach health and nutrition to second through fifth grade-level children. The specific objectives of the research project were to evaluate the effect of the program on nutritional knowledge of the benefits of eating fruit and vegetables, nutritional attitudes toward fruit and vegetables, and eating behaviors of children, specifically consumption of fruit and vegetables. Children's nutritional knowledge was measured with an 11-question multiple-choice exam based on the educational activities performed. Children's nutritional attitudes regarding fruit and vegetables were measured with a fruit and vegetable preference questionnaire, and children's eating behaviors were evaluated with an interview question asking them what they ate for a snack that day. After participating in the nutritional program, children's knowledge about the benefits of eating fruit and vegetables significantly improved, but there were no significant differences found in participants' attitude scores toward fruit and vegetables. However, the participants did report eating healthier snacks after participation in the nutritional program.

$\mathrm{N}$ utrition plays a critical role in the life of a child because of the impact it can have on growth, development, and the ability to learn (Byrd-Bredbenner et al., 1993). Proper childhood nutrition not only contributes to mental, physical, and emotional health, but also to the level of health a person has as an adult.

Because of increasing concerns about Americans' health, a "National Action Plan to Improve the American Diet" has been developed to achieve the goals of "Healthy People 2000: National Health Promotion and Disease Prevention Objectives" (Mullis et al., 1995). One of the main goals of Healthy People 2000 is called " 5 A Day for Better Health," which encourages the consumption of five or more servings of fruit and vegetables per day (Domel et al., 1993b). This type of program promotes the idea that a healthy diet established early in life can help lessen the chances of developing major health problems like cardiovascular disease and cancers in

${ }^{1}$ Research Assistant, Department of Horticultural Sciences, Texas A\&M University, College Station, TX $77843-2133$

${ }^{2}$ Associate Professor, Department of Agriculture, Texas State University, San Marcos, TX 78666.

${ }^{3}$ Professor, Department of Horticultural Sciences, Texas A\&M University, College Station, TX 77843-2133. later years. Fruit and vegetables are important components of a healthy diet, providing many essential vitamins and minerals (Dittus et al., 1995). While the consumption of fruit and vegetables by the average American seems to be increasing, there are still many populations that need to be reached.

Research has indicated that children ages 6 to 12 years eat an average of 2.13 fruit and vegetables per day, which is less than half of the recommended servings (Cullen et al., 2001). Changing demographics, including a rising number of single-parent households, have affected children in a number of ways, including their dietary patterns (Kennedy and Goldberg, 1995). Social aspects of culture and demographic factors affect where, when, what, and with whom children eat. Individuals in low income and low education categories, especially males, have more barriers to fruit and vegetable intake (Dittus et al., 1995). Activities in a familiar situation may help children to become more knowledgeable about fruit and vegetables. By exposing children to what fruit and vegetables are and by gaining experience in preparing these fruit and vegetables, children's consumption of fruit and vegetables may increase.

There are a number of curricular approaches that can be used to teach nutrition education, one being horticulture. A study of a horticulture gardening program for seniors found improved nutritional attitudes and consumption of fruit for those participating (Hackman and Wagner, 1990). Another study in an urban setting found that individuals who gardened ate more vegetables when compared to those who did not garden (Blair et al., 1991). In addition, a study of elementary school children in southern Texas found improved snack preferences for those who participated in an educational program on the nutritional benefits of citrus fruit (Koch et al., 2005).

One objective of this research study was to evaluate the effect of a nutritional education program, Health and Nutrition from the Garden (Genzer et al., 2001), on nutritional knowledge of children, specifically knowledge about the benefits of eating fruit and vegetables. Additional objectives of the study included evaluating the effect of the nutritional education program on nutritional attitudes and eating behaviors of children as they related to fruit and vegetables.

\section{Materials and methods}

Activity GUIDE. The nutrition education program used for this research study was a program developed for children called Health and Nutrition from the Garden (Genzer et al., 2001) that is intended to teach children how to eat healthfully while working on a limited budget. The Texas Agricultural Extension Service developed this nutrition education program in cooperation with The Better Living for Texans (BLT) program. The BLT program strives to educate limited resource clientele on how to make healthier eating choices on a limited income.

Health and Nutrition from the Garden (Genzer et al., 2001) consists of six concepts, including thrifty gardens, basic gardening, growing techniques, $\mathrm{ABCs}$ of healthy eating, healthy snacks, and food safety. Each concept is demonstrated by approximately six activities concentrating on different issues dealing with health and nutrition. Twelve activities from the six concepts of the Health and Nutrition from the Garden program were evaluated for this study. These 12 activities address issues such as fiber in the diet, budgeting, gardening, plant 
needs, healthy eating according to the food guide pyramid, label reading, and storage methods.

Program Delivery. This research study took place from May through August in cooperation with four counties in Texas, including Angelina, Hidalgo, Martin, and Tarrant counties. The BLT program agents of the participating counties volunteered to be a part of this study, and BLT program clients volunteered their children to participate in the study. The researcher visited each county to train the agents and volunteers in leading the activities. Within each county, the delivery times, availability, and format of the program were at the discretion of the county agent. For instance, one county offered the program in a l-week summer camp format. One county offered the program once per week over the course of 12 weeks, while another offered it every morning for 1 week.

Sample population. Participating children included second through fifth graders. One hundred and thirtyfive participants completed a pretest questionnaire prior to participating in the program. A midtest questionnaire was administered after the children had participated in the first six activities. A posttest questionnaire was administered after children completed all 12 activities.

InSTRUMENTATION. The instrument used for this study consisted of three segments. The first segment of the instrument was a written exam made up of 11 true/false and multiple-choice questions based on the 12 activities performed (Table 1). These questions dealt with specific knowledge from the 12 activities presented to the children. Each answer in this section received a score. Questions 3,10 , and 11 had multiple correct answers; therefore, these questions were worth more points. The scores were summed, so children received a knowledge score ranging from 0 to 18 points. Higher scores indicated higher retention and understanding of the information presented in the 12 activities. A Cronbach's alpha reliability test for the knowledge section of the questionnaire resulted in a coefficient of 0.65 , showing it to have an acceptable level of internal consistency (Sapp and Jensen, 1997).

The second segment of the research instrument was a modified version of the Fruit and Vegetable
Table 1. Knowledge questionnaire developed for children participating in the Health and Nutrition from the Garden (Genzer et al., 2001) program and study.

\begin{tabular}{lc}
\hline Question & Possible points \\
\hline
\end{tabular}

1. Can someone use coupons to help them save money on food

at the grocery store?

Yes $^{y}$ or No

2. Should you always wash fruits and vegetables before eating them? I Yes $^{y}$ or No

3. What are some methods of food storage? (Circle all that are correct) 4
a. Freezing ${ }^{y}$
b. Leaving outside
c. Leaving on your counter
d. Putting in the pantryy
e. Canning ${ }^{y}$
f. Refrigeration ${ }^{y}$

4. When can gardening help us to get fruits and vegetables?
a. During summer only
b. Throughout the yeary
c. During fall only
d. During winter only

5. To stay healthy, how many servings of fruits and vegetables should we eat each day?
a. One
b. Two
c. Three
d. Four
e. Five ${ }^{y}$

6. Can gardening help you save money? Yes $^{y}$ or No

7. One way to save money is to
a. Harvest seeds to use next year ${ }^{y}$
b. Buy new seeds every year
c. Go to the grocery store every day
d. Buy the most expensive items

8. What is the most important meal of the day?
a. Breakfast
b. Lunch
c. Dinner
d. Snack

9. Fiber is an important nutrient for our body. We get fiber from the foods we eat. What is a good source of fiber?
a. An appley
b. A soft drink
c. Smooth peanut butter
d. Cheese

10. What do plants need to live? (Circle all that are correct)
a. A computer
b. Water ${ }^{\mathrm{y}}$
c. Paper
d. Juice
e. Light $^{y}$
f. Air $^{y}$
g. Magazines

11. What do labels on food packages tell us? (Circle all that are correct)

a. Amount of nutrients the food contains

b. What ingredients are in ity

c. How to make a salad

d. What a preservative is

e. How many servings are in the package ${ }^{y}$

${ }^{2}$ Points were allocated for correct answer and summed for a score ranging from 0 to 18 .

Correct answer. 
Preference Questionnaire, which measures students' nutritional attitudes regarding fruit and vegetables (Domel et al., 1993a). This section of the questionnaire measured questions on a Likert-type scale (Likert, 1967). Children observed a listing of common fruit and vegetables by name and rated whether they preferred that particular fruit or vegetable or not. The four possible responses to each fruit or vegetable and the points associated with each response included: $3=$ "I like this a lot," 2 = "I neither like nor dislike," 1 = "I do not like this," or $0=$ "I have never tried." The points within this section were summed so that each child had an overall score on this section from 0 to 60 points. Higher scores indicated greater fruit preference/attitude. A Cronbach's alpha reliability test indicated a reliability of 0.80 for the preference section of the Fruit and Vegetable Questionnaire, showing it to have an acceptable level of internal consistency (Sapp and Jensen, 1997).

The third segment of the instrument consisted of five interview questions (Table 2). Questions 1 through 4 evaluated students' knowledge of the 12 activities performed. Question 5 evaluated children's eating habits by asking them the type of snack they had the day before. Each question had multiple answers; therefore, a scoring rubric was created. The child received one point for each correct answer on each question. On the question regarding snack preference, the child received one point for a fruit or vegetable and zero points for a non-fruit or vegetable. The points were summed so each child received an interview score ranging from 0 to 22. The higher the score, the better the knowledge/behavior change. The agent/volunteer scribed children's answers to questions. A Cronbach's alpha reliability test indicated that for this sample and study the reliability of the interview section resulted in a coefficient of 0.72 , showing it to have an acceptable level of internal consistency (Sapp and Jensen, 1997).

The questionnaire also included a cover sheet that gathered demographic information from children, including gender, grade, ethnicity, and place of residence, as well as their name. The name of the student was used only to correctly match pretest, midtest, and posttest at the end of the study.

Data Analysis. Each county received the testing material by hand or through the mail, depending on location. After the testing time, the material was mailed to the researcher. The researcher then matched the test based on the demographic sheet and coded the test for confidentiality. The data collected were analyzed using SPSS (SPSS for Windows 10.0; SPSS, Chicago). Statistical procedures included general factorial tests of comparison and paired $t$ tests.

\section{Results and discussion}

Each section of the nutrition questionnaire was analyzed separately to investigate differences in knowledge, fruit preference, and snack preference. Only students participating in all three testing dates for each section were included in the analyses. Therefore, while 135 children initially took the pretest questionnaire at the onset of the study, only 56 children completed all three surveys including the pretest, midtest, and posttest surveys and could be included within the sample.

Knowledge section. Paired $t$ tests were performed to investigate the differences between pretest, midtest, and posttest scores on the knowledge section of the nutrition questionnaire. Significant differences were found between the pretest and midtest, pretest and posttest, and the midtest and posttest (Table 3 ). However, the most improvement (3.69 points) occurred in the children's knowledge scores after their participating in all of the activities (posttest) compared to their pretest scores (Table 3 ). It

Table 2. Paired $t$ test comparison of the pretest and posttest interview section scores of children participating in the Health and Nutrition from the Garden (Genzer et al., 2001) program and study.

\begin{tabular}{|c|c|c|c|c|c|c|}
\hline Question $^{\mathrm{z}}$ & $\begin{array}{l}\text { Cases } \\
\text { (no.) }\end{array}$ & $\begin{array}{l}\text { Mean score } \\
(0-22 \text { scale })\end{array}$ & SD & df & $t$ & $P$ \\
\hline \multicolumn{7}{|c|}{$\begin{array}{l}\text { 1. Place foods in the appropriate spots on the food } \\
\text { guide pyramid. What foods should we eat more of? }\end{array}$} \\
\hline Pretest & 56 & 1.63 & 1.07 & 55 & -7.100 & $0.000 *$ \\
\hline Posttest & 56 & 2.93 & 1.63 & & & \\
\hline \multicolumn{7}{|c|}{$\begin{array}{l}\text { 2. Do we need to eat foods from all parts of the food } \\
\text { guide pyramid? Why? }\end{array}$} \\
\hline Posttest & 56 & 1.70 & 0.71 & & & \\
\hline \multicolumn{7}{|c|}{$\begin{array}{l}\text { 3. How can you get foods you don't have without } \\
\text { buying them? }\end{array}$} \\
\hline Pretest & 56 & 0.93 & 0.37 & 55 & -1.627 & 0.109 \\
\hline Posttest & 56 & 1.04 & 0.33 & & & \\
\hline \multicolumn{7}{|c|}{ 5. What did you have for a snack yesterday? } \\
\hline Pretest & 56 & 0.16 & 0.37 & 55 & -3.644 & $0.001^{*}$ \\
\hline Posttest & 56 & 0.41 & 0.50 & & & \\
\hline
\end{tabular}

${ }^{2}$ Each question had multiple answers. Correct answers received 1 point on each question. On the question regarding snack preference, the child received one point for a fruit or vegetable and zero points for a non-fruit or vegetable. The points were summed and scores ranged from 0 to 22 .

* Significant at $P \leq 0.05$. 
would be expected that more exposure to the material within the Health and Nutrition from the Garden program would further improve participants' knowledge of the benefits of eating fruit and vegetables. A solid foundation of knowledge of good food choices is a defining component of one of the major underlying theories in nutrition education. The knowledge, attitude, behavior (KAB) communication model (Contento et al., 1992) is a three-step model that incorporates the idea that knowledge leads to better attitudes, which in turn, lead to better behaviors. The knowledge of what should be eaten (fruit and vegetables) and why (for better health), is thought to lead to better attitudes toward fruit and vegetables and, in turn, increase consumption (Cullen et al., 2001; Foerster et al., 1998).

Additional tests were performed to see if there were any statistically significant differences between age level, gender, ethnicity, or county, but no statistically significant differences were found. However, a repeated measures test was performed and found that each age level and gender significantly improved their scores over the course of the program (Table 4). These results indicate that the Health and Nutrition in the Garden curriculum is effective for younger as well as older children, and for both males and females.

Fruit preference SECtion. Paired $t$ tests were performed to investigate the variation between pretest, midtest, and posttest scores on the fruit and vegetable preference section of the questionnaire. Fruit and vegetable preference scores of children did not significantly improve during or after participating in the program (Table $5)$. However, all of the preference test scores were high, indicating that children had a positive attitude toward fruit and vegetables before, during, and after participating in the program. This was an encouraging finding since food preferences, or nutritional attitudes, have a strong relationship to food consumption (Skinner et al., 1998). Children eat what they like (Skinner et al., 1998). However, food preferences are influenced by several factors including taste, availability, environmental variables (Hearn et al., 1998), cost, and family acceptance (Dittus et al., 1995), so even if a child prefers
Table 3. Paired $t$ test comparison of the knowledge scores of children participating in the Health and Nutrition from the Garden (Genzer et al., 2001) program and study.

\begin{tabular}{lcccccc}
\hline Test & $\begin{array}{c}\text { Cases } \\
\text { (no.) }\end{array}$ & $\begin{array}{c}\text { Mean score } \\
(\mathbf{0}-\mathbf{1 8} \text { scale })\end{array}$ & sD & df & $t$ & $P$ \\
\hline Pretest & 56 & 11.88 & 3.07 & 55 & -7.561 & $0.000^{*}$ \\
Midtest & 56 & 15.00 & 1.93 & & & \\
Pretest & 56 & 11.88 & 3.07 & 55 & -8.686 & $0.000^{*}$ \\
Posttest & 56 & 15.57 & 1.66 & & & \\
Midtest & 56 & 15.00 & 1.93 & 55 & -2.479 & $0.016^{*}$ \\
Posttest & 56 & 15.57 & 1.66 & & & \\
\hline
\end{tabular}

* Significant at $P \leq 0.05$.

Table 4. Repeated measures comparison of pretest, midtest and posttest knowledge scores of male and female and different age categories of children participating in the Health and Nutrition from the Garden (Genzer et al., 2001) program and study.

\begin{tabular}{lcccccc}
\hline Age & $\begin{array}{c}\text { Cases } \\
\text { (no.) }\end{array}$ & $\begin{array}{c}\text { Mean score } \\
(\mathbf{0}-18 \text { scale })\end{array}$ & SD & df & $t$ & $P$ \\
\hline Under 8 & & & & & & \\
$\quad$ Pretest & 16 & 11.13 & 2.87 & 2 & 31.071 & $0.000^{*}$ \\
Midtest & 16 & 14.88 & 1.36 & & & \\
Posttest & 16 & 15.56 & 1.63 & & & \\
9-10 & & & & & & \\
Pretest & 23 & 12.17 & 3.39 & 2 & 13.391 & $0.000^{*}$ \\
Midtest & 23 & 14.52 & 2.09 & & & \\
Posttest & 23 & 15.17 & 1.87 & & & \\
Over 10 & & & & & & \\
Pretest & 17 & 12.18 & 2.83 & 2 & 20.810 & $0.000^{*}$ \\
Midtest & 17 & 15.76 & 2.02 & & & \\
Posttest & 17 & 16.12 & 1.27 & & & \\
Female & & & & & \\
Pretest & 35 & 11.80 & 3.05 & 2 & 48.235 & $0.000^{*}$ \\
Midtest & 35 & 15.40 & 1.83 & & & \\
Posttest & 35 & 15.74 & 1.54 & & & \\
Male & & & & & & \\
Pretest & 21 & 12.00 & 3.18 & 2 & 14.124 & $0.000^{*}$ \\
Midtest & 21 & 14.33 & 1.93 & & & \\
Posttest & 21 & 15.29 & 1.85 & & & \\
\hline
\end{tabular}

* Significant at $P \leq 0.05$.

Table 5. Paired $t$ test comparison of pretest and midtest, pretest and posttest, and midtest and posttest preference inventory scores of children participating in the Health and Nutrition from the Garden (Genzer et al., 2001) program and study.

\begin{tabular}{lcccccc}
\hline Test & $\begin{array}{c}\text { Cases } \\
\text { (no.) }\end{array}$ & $\begin{array}{c}\text { Mean score } \\
(\text { 0-60 scale) }\end{array}$ & SD & df & $t$ & $P$ \\
\hline Pretest & 48 & 45.69 & 7.57 & 47 & 0.029 & 0.977 \\
Midtest & 48 & 45.67 & 8.28 & & & \\
Pretest & 48 & 45.69 & 7.57 & 47 & -0.944 & 0.350 \\
Posttest & 48 & 46.44 & 8.14 & & & \\
Midtest & 48 & 45.67 & 8.28 & 47 & -1.245 & 0.219 \\
Posttest & 48 & 46.44 & 8.14 & & & \\
\hline
\end{tabular}


Table 6. Paired $t$ test comparison of pretest and midtest, pretest and posttest, and midtest and posttest interview section scores of children participating in the Health and Nutrition from the Garden (Genzer et al., 2001) program and study.

\begin{tabular}{lcccccc}
\hline Test & $\begin{array}{c}\text { Cases } \\
\text { (no.) }\end{array}$ & $\begin{array}{c}\text { Mean score } \\
(\mathbf{0}-22 \text { scale })\end{array}$ & SD & df & $t$ & $P$ \\
\hline Pretest & 41 & 5.37 & 1.56 & 40 & -3.988 & $0.000^{*}$ \\
Midtest & 41 & 6.44 & 2.37 & & & \\
Pretest & 41 & 5.37 & 1.56 & 40 & -5.279 & $0.000^{*}$ \\
Posttest & 41 & 6.76 & 2.26 & & & \\
Midtest & 41 & 6.44 & 2.37 & 40 & -1.305 & 0.199 \\
Posttest & 41 & 6.76 & 2.26 & & & \\
\hline
\end{tabular}

*Significant at $P \leq 0.05$.

fruit and vegetables, other factors may inhibit actual consumption.

InTERVIEW SECTION. Pretest, midtest, and posttest scores for the interview portion of the questionnaire were compared using paired $t$ tests. Statistically significant differences were found between the pretest and midtest scores, and between the pretest and posttest scores (Table 6). To help determine which questions had the most improved scores, questions were analyzed separately (Table 2 ). No statistically significant differences were found on response scores for questions 2, 3, and 4. However, students significantly improved their scores by 1.3 points on Question 1, which asked them to place food items in their correct category on the food guide pyramid. These results indicated that students had a better understanding of the food groups after participating in the Health and Nutrition from the Garden program. However, often there is a gap between the understanding and awareness and the actual consumption of fruit and vegetables.

Question 5 was a snack consumption question asking the students what they ate for a snack that day. After participating in the nutrition program, students reported eating a healthy snack more often when compared to the number of youth who reported eating a healthy snack prior to starting the program. This supports past research that found that increased exposure through various garden or other horticultural activities increased consumption of fruit and vegetables (Blair et al., 1991; Hackman and Wagner, 1990).

Small improvements in eating habits are important to America's youth today. Experts are promoting healthy diets by recommending plenty of ex- ercise, reduced fat consumption, and increased fruit and vegetable consumption (Griffiths et al., 1996). One sign of poor dietary habits of youth is the increase of obesity in children. More than $25 \%$ of young children are obese and nearly one-third are overweight (Dietz, 1991). On average, childhood obesity is now more common than the occurrence of underweight children (Kennedy and Goldberg, 1995). One explanation for this might be the noted decrease in the physical activity level of children due to the increases in technology (McPherson et al., 1995). Another explanation of the rise in obesity in children may be the increase in high fat consumption and a decrease in fruit and vegetable consumption, as well as other recommended foods (McPherson et al., 1995). The results of this research indicated that the Health and Nutrition from the Garden program improved the knowledge and food choices made by the participating youth.

\section{Conclusions}

Children participating in activities from Health and Nutrition from the Garden had improved knowledge concerning the benefits of eating fruits and vegetables, and demonstrated an increase in healthier snack consumption after the study. The last finding is very encouraging, since it has been reported that increasing fruit and vegetable consumption as snacks is one important way to improve the nutritional habits of children (Kennedy and Goldberg, 1995). Children's preferences toward fruit and vegetables did not significantly improve during or after participating in the program. This supported research that found no changes in children's preferences for vegetables while participating in a gardening after-school program (Poston et al., 2005).

Small changes in knowledge and consumption of children participating in the program may be important to note since poor dietary behaviors have been associated with many physical problems, including, anemia obesity, and high blood cholesterol (Foerster et al., 1998). In addition, poor dietary practices have been shown to affect mental growth, academic performance, and physical growth and to cause delays in social development (Brown and Sherman, 1995). Most personal food and exercise habits that continue throughout life are established by the age of 15 years (DiNubile, 1993), and adults who reported eating five servings of fruit and vegetables daily generally stated that these habits were established in childhood (Foerster et al., 1998). Since eating habits and patterns are formed early in life, children are an important target for interventions to change nutrition behavior (Cullen et. al., 2001).

\section{Literature cited}

Blair, D., C.C. Giesecke, and S. Sherman. 1991. Dietary, social and economic evaluation of the Philadelphia Urban Gardening Project. J. Nutr. Educ. 23:161-167.

Brown, J.L. and L.P. Sherman. 1995. Hunger as a public health issue, p. 41-53. In: M.D. Simko, C. Cowell, and J.A. Gilbride (eds.). A comprehensive guide for planning intervention. 2nd ed. Aspen Publ., Gaithersbug, Md.

Byrd-Bredbenner, C., M.L. Marecic, and J. Bernstein. 1993. Development of a nutrition education curriculum for Head Start children. Soc. Nutr. Educ. 25(3):134-139.

Contento, I.R., A.D. Manning, and B. Shannon. 1992. Research perspective on school-based nutrition education. J. Nutr. Educ. 24:247-259.

Cullen, K.W., T. Baranowski, L. Rittenberry, C. Cosart, D. Hebert, and C. de Moor. 2001. Child-reported family and peer influences on fruit, juice and vegetable consumption: Reliability and validity of measures. Health Educ. Res. 16:187-200.

Dietz, W. 1991. Factors associated with childhood obesity. Nutrition 7:290-291.

DiNubile, N.A. 1993. Youth fitness-problems and solutions. Preventive Medicine 22:589-594. 
Dittus, K.L., V.N. Hillers, and K.A. Beerman. 1995. Benefits and barriers to fruit and vegetable intake: Relationship between attitudes and consumption. J. Nutr. Educ. 27:120-126.

Domel, S.B, T. Baranowski, H. Davis, S.B. Leonard, P. Riley, and J. Baranowski. 1993a. Measuring fruit and vegetable preferences among $4^{\text {th }}$ - and $5^{\text {th }}$ - grade students. Preventive Medicine 22:866-879.

Domel, S.B., T. Baranowski, H. Davis, W.O. Thompson, S.B. Leonard, P. Riley, J. Baranowski, B. Dudovitz, and M. Smyth. 1993b. Development and evaluation of a school intervention to increase fruit and vegetable consumption among $4^{\text {th }}$ and $5^{\text {th }}$ grade students. J. Nutr. Educ. 25:345-349.

Foerster, S.B., J. Gregson, D.L. Beall, M. Hudes, H. Magnuson, S. Livingston, M.A. Davis, A.B. Joy, and T. Garbolino. 1998. The California children's 5 a day-power play! campaign: Evaluation of a large-scale social marketing initiative. Family Community Health 21(1):46-64.

Genzer, S., R. Seagraves, L. Whittlesey, C.W. Robinson, and S. Koch. 2001. Junior Master Gardener Level 1 Golden Ray-Health and nutrition from the garden. Newman Publ., Bryan, Texas.
Griffiths, K., H. Adlercreutz, P. Boyle, L. Denis, R.I. Nicholson, and M.S. Morton. 1996. Nutrition and cancer. Isis Medical Media, Oxford, U.K.

Hackman, R.M. and E.L. Wagner. 1990. The senior gardening and nutrition project: Development and transport of a dietary behavior change and health promotion program. J. Nutr. Educ. 22:262-270.

Hearn, M.D., T. Baranowski, J. Baranowski, C. Doyle, M. Smith, L.S. Lin, and K. Resnicow. 1998. Environmental influences on dietary behavior among children: Availability and accessibility of fruits and vegetables enable consumption. J. Health Educ. 29:26-32.

Kennedy, E. and J. Goldberg. 1995. What are American children eating? Implications for public policy. Nutr. Rev. 53:111-126.

Koch, S., S. Lineberger, and J.M. Zajicek. 2005. Can an educational program on the nutritional benefits of citrus fruit positively influence the nutritional attitudes of children. HortTechnology 15(3):468-471.

Likert, R. 1967. The method of constructing an attitude scale. In: M. Fishbein (ed.). Readings in attitude theory and measurement. Wiley, New York.
McPherson, R.S., D. Montogomery, and M. Nichman. 1995. Nutritional status of children: what do we know? Soc. Nutr. Educ. 27(5):225-234.

Mullis, R.M., A. Owen, and L. Blaskovich. 1995. National action conference on healthy eating for children: A policy dialogue. J. Nutr. Educ. 27(5):222-224.

Poston, S.A., C.A. Shoemaker, and D.A. Dzewaltowski. 2005. A comparison of a gardening and nutrition program with a standard nutrition program in an out-of-school setting. HortTechnology 15(3):463-467.

Sapp, S.G. and H.H. Jensen. 1997. Reliability and validity of nutrition knowledge and diet-health awareness tests developed from the 1989-1991 diet and health knowledge surveys. J. Nutr. Educ. 29:63-72.

Skinner, J., B.R. Carruth, J. Moran III, K. Houck, J. Schmidhammer, A. Reed, F. Coletta, R. Cotter, and D. Ott. 1998. Toddlers' food preferences: concordance with family members' preference. J. Nutr. Educ. 30:17-22. 